\title{
Adherence to iron supplements among women receiving antenatal care at Mulago National Referral Hospital, Uganda-cross-sectional study
}

\author{
Tusuubira S. Kiwanuka, Sam Ononge, Paul Kiondo and Fatuma Namusoke* ${ }^{*}$
}

\begin{abstract}
Background: Antenatal iron supplementation is a cost effective way of reducing iron deficiency anaemia among pregnant women in resource limited countries like Uganda. Poor adherence to iron supplements has limited its effectiveness in reducing maternal anaemia as evidenced by the high burden of iron deficiency anemia in Sub-saharan Africa. The aim of this study was to determine the level of and factors associated with adherence to iron supplementation among women attending antenatal clinic at Mulago National Referral Hospital, Kampala, Uganda.

Methods: Three hundred and seventy pregnant women were recruited in a cross sectional survey in Mulago National Referral Hospital antenatal clinic after informed consent between February and April 2014. Levels of adherence to iron supplements were assessed using visual analogue scale and factors associated collected using an interviewer administered questionnaire.
\end{abstract}

Results: About 12\% (11.6\%) of the mothers attending the antenatal clinic adhered to iron supplements over 30 day period. Mothers who had had four or more antenatal visits prior to the survey [odds ratio $(\mathrm{OR})=1.49,95 \%$ confidence interval (Cl) 1.12-1.97], had more than 2 week supply of iron supplements in the previous visit (OR 2.81, 95\% Cl 1.021.09), prior health education (OR $1.56,95 \% \mathrm{Cl} 1.07-2.29)$ were more likely to adhere to iron supplements. Inadequate drug supplies and fear for side effects were the main reasons why participants missed the iron supplements.

Conclusions: There was low adherence to iron supplements among mothers attending antenatal clinic at Mulago National Referral Hospital. We recommend a national evaluation of adherence to iron supplements and look at ways of increasing adherence.

Keywords: Adherence, Pregnancy, Iron supplementation

\section{Background}

Iron deficiency anaemia (IDA) in pregnancy is associated poor maternal and neonatal outcomes like premature labor, post-partum haemorrhage, low birth weight and poor cognitive development [1]. In Uganda, anaemia in pregnancy is estimated to affect about $33 \%$ of the pregnancies [2]. To prevent morbidity associated with IDA, the Ministry of Health in Uganda recommends use

*Correspondence: namusokefk@yahoo.co.uk

Department of Obstetrics and Gynaecology, School of Medicine, College of Health Sciences, Makerere University, P. O. Box 7072, Kampala, Uganda of daily oral iron and folic acid supplementation during pregnancy and within 6 weeks after delivery [3]. In order to achieve the effectiveness of medication/intervention, it requires up to $80 \%$ adherence [4]. Previous studies on iron adherence have had conflicting results, with some reporting adherence of up to $88 \%$ [5] but with majority reporting low levels of $25-50 \%$ [6-8] which may explain persistence of IDA. There was paucity of data on burden and factors associated with adherence to antenatal iron supplementation in this setting. The purpose of this study was to determine the level of and the factors associated with adherence to iron supplementation among women 
receiving antenatal care at Mulago National Referral Hospital.

\section{Methods}

\section{Study setting and participants}

This study was a cross sectional study conducted on women in second or third trimesters, receiving antenatal care at Mulago National Referral Hospital from February to April 2014. The hospital serves as a National Referral Hospitals for Uganda and Makerere University College of Health Sciences teaching hospital. Mulago National Referral Hospital is a government institution which gives free health care services. It has two antenatal clinics, one is a high risk clinic run by the obstetricians/gynaecologists, and low risk clinic managed by midwives. The obstetrician led antenatal clinic serves an average of 130 mothers per day and runs 3 days in a week. The midwife led antenatal clinic caters for an average of $60-80$ women per day for 5 days. Mulago hospital provides the iron supplements at no cost, however, in cases where the prescribed medicines are not available/inadequate supplies at the unit, the clients are given a prescription to buy from a private pharmacy. During the antenatal visits, mothers receive tetanus immunization, health education talks and are counseled for HIV testing. They are given haematinics and antimalarials for prevention of anaemia and malaria respectively.

The women who had had an antenatal visit 30 days or more prior to recruitment and were eligible for receipt of iron supplements on their previous visit were included. Women were excluded if they were allergic to iron supplements. Sample size for prevalence was calculated using the Kish Leslie formula (1965). Non-compliance of $58 \%$ was depicted from a study done in Tanzania to assess adherence for the conventional iron supplements. Adherence of $42 \%$ was found for the conventional iron supplements [12]. With power of $80 \%$, and desired level of precision of $5 \%$, the minimum sample size estimated for the study was 374 participants.

\section{Study procedures}

Data on socio demographic characteristics, obstetric history and health system related characteristics was collected using an interviewer administered questionnaire. Information on age of the women, their education level, marital status and occupation was recorded. The occupation of the mother was used as a proxy for the socioeconomic status. Data on the number of antenatal visits the mother had prior to enrollment (ANC visits), total duration of use of iron supplements, number of iron tablets supplied at the hospital pharmacy during the last ANC and getting health talks on usefulness of iron supplements was collected using an interviewer administered questionnaire.

Adherence to antenatal iron supplements in the last 30 days was assessed using the visual analogue scale. Using a scale, patients were asked to self-assess their level of adherence on a scale of $0-100 \%$ without being observed by the interviewer. Adherence was assessed as good, partial or poor if patients were taking $\geq 90$, $50-90,<50 \%$ of their prescribed pills respectively. For purposes of this analysis, the partially and poorly adherent groups were combined to form the non-adherent group while the group that had good adherence formed the adherent group.

\section{Statistical methods}

The data was entered in Epi-Data software package 3.1 and analysed using STATA version 11 . The dependent variable was adherence to iron supplements and independent variables were the patient (age, parity, marital status, total number of antenatal visits, total duration of use of iron supplements during that pregnancy, education level, occupation) and hospital related factors (number of tablets dispensed at the hospital pharmacy during the last ANC visit, health talks on iron supplements). Descriptive statistics was done to describe the participants and then bivariate and multivariate logistic regression using a backward elimination method to determine factors which were independently associated with good adherence. Statistical significance was put at a $p$ value of less than 0.05 .

\section{Results}

Socio-demographic characteristics of the participants

The median age of the study participants was 27 years and the interquartile range was 8 years. Nearly $27 \%$ $(102 / 370)$ of study participants were primigravidae and $(244 / 370) 66 \%$ of them had post primary education. The details of the baseline characteristics of the participants are summarized in Table 1.

\section{Health system related factors}

Ninety percent of the study participants, (333/370) reported having received iron supplements on their previous antenatal visit. Over $60 \%$ of the participants had attended the antenatal clinic less than four times and $17.6 \%$ had been using iron supplements for more than 90 days. Details on the health related factors in the participants are shown in Table 2.

Very low adherence to iron supplementation in pregnancy Eighty-two percent (304/370) of the participants reported ever missing to take iron supplements during the current pregnancy and the commonest reason was lack of 
Table 1 Demographic characteristics of study participants

\begin{tabular}{|c|c|c|}
\hline Variable & Number $(\mathrm{N}=370)$ & Percentage (\%) \\
\hline \multicolumn{3}{|l|}{ Marital status } \\
\hline Single & 43 & 11.6 \\
\hline Married & 321 & 86.8 \\
\hline Widowed & 4 & 1.1 \\
\hline Separated/divorced & 2 & 0.5 \\
\hline \multicolumn{3}{|l|}{ HIV status } \\
\hline Negative & 332 & 89.7 \\
\hline Positive & 38 & 10.3 \\
\hline \multicolumn{3}{|l|}{ Education status } \\
\hline Primary and below & 126 & 34.0 \\
\hline O'level and above & 244 & 66.0 \\
\hline \multicolumn{3}{|l|}{ Parity } \\
\hline None & 111 & 30.0 \\
\hline One & 75 & 20.3 \\
\hline $2-4$ & 149 & 40.3 \\
\hline$\geq 5$ & 35 & 9.4 \\
\hline \multicolumn{3}{|l|}{ Occupation } \\
\hline Formal & 42 & 11.4 \\
\hline Informal & 144 & 38.9 \\
\hline None & 184 & 49.7 \\
\hline
\end{tabular}

drugs $(134 / 370)$ and followed by forgetting to take medication (93/370). Using the VAS, good adherence (taking $90 \%$ or more of prescribed iron supplements) over 30 days was $11.6 \%$ (43/370), with (203/370) 54.9\% having partial adherence and (124/370) 33.5\% having poor adherence. The partial and poorly adherent group were combined to form the non-adherent group which constituted (327/370) $88.4 \%$ of the study participants. The participants who had had more than four antenatal visits and who received health talks on the usefulness of iron supplements were more likely to adhere. The details on other factors associated with adherence at bivariate analysis are presented in Table 3.

\section{Individual and institutional factors associated with adherence to iron supplements}

Participants who had attended the antenatal clinic four or more times before recruitment (OR 1.49 95\% CI $1.12-1.97)$, receiving a supply of iron tablets of more than 14 days (OR 1.05; 95\% CI 1.02-1.09), receiving health education about the supplements (OR 1.56, 95\% CI 1.07-2.29). The participants who were in informal employment and unemployed were more likely to adhere to iron supplements (OR 11.80, 95\% CI 1.45-96.13). Details on all the factors which remained significant after multivariate analysis are shown in Table 4.

\section{Discussion}

Despite the high burden of anaemia in pregnancy in low resource setting and effectiveness of antenatal iron supplementation, we found that only $12 \%$ of participants adhered to iron supplements. Similarly very low adherence to iron supplements has been shown in the Scandinavia of 27\% [8]. Conversely, higher levels of adherence to iron supplements has been reported in Nigeria and Senegal of 88 and $58 \%$ respectively [5, 7]. The adherence to iron supplements in this study was very low compared to that reported in other African countries. It is possible that the adherence levels seen in Senegal were due to the fact that a lower cut off (70\%) was used to assess adherence. The differences in levels of adherence can be explained by the different methods used in data collection and definition of adherence in the studies. It has been suggested adherence to medication should be defined as a patients taking $90 \%$ or more of prescribed medicine [9]. The general weakness of most studies assessing adherence is the use of self reports in measurement of adherence. The challenge with self reports is that patients tend to overestimate their adherence [9-11]. For example in a study done in Iran, $80 \%$ of the pregnant women reported taking their iron supplements but this could only be confirmed in $21 \%$ of participants after examining the stool samples [12].

Using the visual analogue scale, about $12 \%$ of participants adhered to their iron supplements in this study. VAS is a tool used in data collection of adherence where the participant judges herself/himself on a given scale in absence of the interviewer has been suggested to be reliable and cheap. Previous studies done to assess adherence to ARVs, anti-TB drugs and pain assessment have identified the VAS as a reliable method of assessing adherence in resource limited settings [10, 13]. Other methods like pill count have been used but it is time consuming.

One of the main findings in our study was that mothers were not getting enough iron supplements to last them till the next visit were less likely to adhere to the supplements as prescribed. Galloway et al. [14] in a systemic review identified supplies as the main reason that women don't comply to their iron supplements. In a study done in Vietnam, supplies were identified as the most important factor affecting adherence [15]. Most women, if provided with adequate iron supplements, whether pills or syrup are likely to take them $[14,16]$. The burden of insufficient supplies of iron supplements is still reflected in the USAID cross country report across 33 developing countries with less than $50 \%$ of pregnant women having bought or received iron supplements in the preceding pregnancy in the eight African countries studied [4].

Another factor that was independently associated with adherence was providing women with information on 
Table 2 Health system related factors in relation to adherence

\begin{tabular}{|c|c|c|c|c|}
\hline Variable & Adherence (p0) & Non adherence (p1) & Total N (\%) & $p$ value (for $p 0-p 1$ ) \\
\hline \multicolumn{5}{|l|}{ Number of ANC visits } \\
\hline$<4$ visits & $202(61.8)$ & $20(46.6)$ & $222(60.2)$ & 0.06 \\
\hline$\geq 4$ visits & $124(38.1)$ & $23(53.4)$ & $147(39.8)$ & 0.06 \\
\hline \multicolumn{5}{|c|}{ Received iron at previous visit } \\
\hline Yes & $291(89.0)$ & $42(97.7)$ & $333(90.0)$ & 0.07 \\
\hline No & $36(11.0)$ & $1(2.3)$ & $37(10.0)$ & 0.07 \\
\hline \multicolumn{5}{|l|}{ Counseled on iron before } \\
\hline Yes & $117(35.8)$ & $25(58.1)$ & $142(38.4)$ & 0.00 \\
\hline No & $220(64.2)$ & $18(41.9)$ & $228(61.6)$ & 0.00 \\
\hline \multicolumn{5}{|l|}{ Duration of use of iron } \\
\hline$\leq 90$ days & $272(83.2)$ & $33(76.7)$ & $305(82.4)$ & 0.29 \\
\hline$>90$ days & $55(16.8)$ & $10(23.3)$ & $65(17.6)$ & 0.29 \\
\hline \multicolumn{5}{|c|}{ Where do you get drugs from } \\
\hline Hospital pharmacy & $286(87.5)$ & $38(88.4)$ & $324(87.6)$ & 0.87 \\
\hline Private clinic/local store & $41(12.5)$ & $5(11.6)$ & $46(13.4)$ & 0.87 \\
\hline \multicolumn{5}{|c|}{ Do you always get your drugs } \\
\hline Yes & $247(75.5)$ & $38(88.4)$ & $285(77.0)$ & 0.06 \\
\hline No & $80(24.5)$ & $5(11.6)$ & $85(23)$ & 0.06 \\
\hline \multicolumn{5}{|c|}{ Iron tablets received on last visit } \\
\hline$\leq 14$ tablets & $128(39.2)$ & $8(18.6)$ & $136(36.8)$ & 0.01 \\
\hline$>14$ tablets & $199(60.8)$ & $35(81.4)$ & $234(63.2)$ & 0.01 \\
\hline \multicolumn{5}{|c|}{ Are you taking other medication? } \\
\hline Yes & $75(22.9)$ & $16(37.2)$ & $91(24.6)$ & 0.04 \\
\hline No & $252(77.1)$ & $27(62.8)$ & $279(75.4)$ & 0.04 \\
\hline \multicolumn{5}{|l|}{ Reason for missing } \\
\hline Side effects & $51(15.6)$ & $0(0.0)$ & $51(13.8)$ & 0.00 \\
\hline Too many drugs & $5(1.5)$ & $1(2.3)$ & $6(1.6)$ & 0.69 \\
\hline I forgot & $90(27.5)$ & $3(7.0)$ & $93(25.1)$ & 0.00 \\
\hline No drugs & $129(39.4)$ & $5(11.6)$ & $134(36.2)$ & 0.00 \\
\hline Not important & $20(6.1)$ & $0(0.0)$ & $20(5.4)$ & 0.09 \\
\hline Other & $32(9.8)$ & $34(79.1)$ & $66(17.8)$ & 0.00 \\
\hline
\end{tabular}

importance of iron supplements through health talks. Previous studies have shown that providing mothers with information is one of the ways to improve the effectiveness of iron supplementation programmes [17, 18]. Patients who know why they are taking their medication and how to deal with the possible complications that may arise are likely to adhere to their medications $[14,18,19]$. Health talks during pregnancy are a very good avenue for conveying massages to the pregnant women.

Pregnant women who had attended the antenatal clinic four or more times were more likely to adhere to their iron supplements than their counterparts after controlling all factors. In a cross country survey carried out in 33 developing countries in Africa, Asia and Latin America, there was no statistically significant correlation between the median number of ANC visits that a mother had and the number of days women consumed their iron tablets [16]. Prior studies have shown that the number of antenatal visits had no added advantage to maternal welfare when compared to the four ANC visits recommended by WHO provided there were no maternal complications [20]. The possible explanation is that, women who attended more than four times are likely to have had a complicated pregnancy and therefore adherence issue discussed with physician.

From our study, side effects were one of the main reasons that mothers gave for failing to adhere to their iron supplements. There's conflicting evidence regarding the impact of side effects on adherence to iron supplements. While some studies show that side effects are actually the main reason why some mothers stop taking their drugs, others argue otherwise. In a study by Nir Melamed 
Table 3 Factors associated with adherence to iron supplements-bivariate analysis

\begin{tabular}{|c|c|c|c|c|c|}
\hline Variable & $\begin{array}{l}\text { Non adher- } \\
\text { ence } \mathrm{N}(\%)\end{array}$ & $\begin{array}{l}\text { Adherence } \\
\mathrm{N}(\%)\end{array}$ & OR & $95 \% \mathrm{Cl}$ & $\mathrm{p}$ value \\
\hline \multicolumn{6}{|c|}{ Number of ANC visits* } \\
\hline $\begin{array}{l}<4 \text { ANC } \\
\text { visits }\end{array}$ & $202(61.8)$ & $20(46.6)$ & 1.0 & & \\
\hline $\begin{array}{c}\geq 4 \text { ANC } \\
\text { visits }\end{array}$ & $125(38.2)$ & $23(53.4)$ & 1.87 & $0.99-3.55$ & 0.05 \\
\hline \multicolumn{6}{|c|}{ Received iron at previous visit* } \\
\hline Yes & $291(89.0)$ & $42(97.7)$ & 1.0 & & \\
\hline No & $36(11.0)$ & $1(2.3)$ & 0.19 & $0.02-0.76$ & 0.11 \\
\hline \multicolumn{6}{|c|}{ Health talk on supplements* } \\
\hline Yes & $107(28.9)$ & $25(58.1)$ & 1.0 & & \\
\hline No & $220(64.2)$ & $18(41.9)$ & 0.40 & $0.21-0.76$ & 0.01 \\
\hline \multicolumn{6}{|c|}{ Duration of use of iron } \\
\hline$\leq 90$ days & $272(83.2)$ & $33(76.7)$ & 1.0 & & \\
\hline$>90$ days & $55(16.8)$ & $10(23.3)$ & 1.50 & $0.69-3.21$ & 0.30 \\
\hline \multicolumn{6}{|c|}{ Do you always get your drugs* } \\
\hline Yes & $247(75.5)$ & $38(88.4)$ & 1.0 & & \\
\hline No & $80(24.5)$ & 5 (11.6) & 0.41 & $0.15-1.07$ & 0.07 \\
\hline \multicolumn{6}{|c|}{ Iron tablets received on last visit* } \\
\hline$\leq 14$ tablets & $128(39.2)$ & $8(18.6)$ & 1.0 & - & - \\
\hline$>14$ tablets & $199(60.8)$ & $35(81.4)$ & 2.81 & $2.26-6.25$ & 0.01 \\
\hline \multicolumn{6}{|c|}{ Are you taking other medication?* } \\
\hline No & 75 (22.9) & $16(37.2)$ & 1.0 & & \\
\hline Yes & $252(77.1)$ & $27(62.8)$ & 1.99 & $1.02-3.89$ & 0.04 \\
\hline
\end{tabular}

*Significant at bivariate analysis

to assess the effect of side effects on compliance, it was found that although $45 \%$ of the participants reported at least one side effect, only $18.3 \%$ attributed discontinuation of therapy to side effects [21]. Different studies that have reviewed iron supplementation programmes show that the proportion of pregnant women who stop taking drugs due to side effects are actually low $[14,16,18,21$, 22]. In Norway, women receiving a placebo complied as well as those on iron supplements, suggesting that side effects may actually not be important [14]. In Tanzania, women who were taking the conventional iron supplements complied less than those who were on a gastric delivery system, indicating that side effects actually did affect compliance [23].

We were surprised to find that formal employment was associated with non adherence, considering the fact that these are usually women of higher education status and better socio-economic status. We would ideally expect these mothers to be better informed about the supplements and be in a better position to buy more drugs in case stocks run out. While our findings are in agreement with those of Nordeng [8], they are contradictory to those of Muture in his study of adherence to anti- TB drugs [11,
Table 4 Factors associated with adherence to iron supplements-multivariate analysis

\begin{tabular}{|c|c|c|c|c|}
\hline Variable & Unadjusted OR & Adjusted OR & $95 \% \mathrm{Cl}$ & $p$ value \\
\hline \multicolumn{5}{|c|}{ Number of ANC visits } \\
\hline$<4$ visits & 1.0 & 1.0 & - & - \\
\hline$\geq 4$ visits & 1.87 & 1.49 & $1.12-1.97$ & $0.01^{\natural}$ \\
\hline \multicolumn{5}{|c|}{ Health talk on supplements } \\
\hline No & 1.0 & 1.0 & - & - \\
\hline Yes & 0.40 & 1.56 & $1.07-2.29$ & $0.02^{\natural}$ \\
\hline \multicolumn{5}{|c|}{ Iron tablets received on last visit } \\
\hline$\leq 14$ tablets & 1.0 & 1.0 & - & - \\
\hline$>14$ tablets & 2.81 & 1.05 & $1.02-1.09$ & $<0.001^{9}$ \\
\hline \multicolumn{5}{|c|}{ Are you taking other medication? } \\
\hline Yes & 1.0 & 1.0 & - & - \\
\hline No & 1.99 & 1.37 & $0.52-3.38$ & 0.48 \\
\hline \multicolumn{5}{|l|}{ HIV status } \\
\hline Negative & 1.0 & 1.0 & - & - \\
\hline Positive & 2.72 & 1.43 & $0.47-4.38$ & 0.52 \\
\hline \multicolumn{5}{|l|}{ Occupation } \\
\hline $\begin{array}{l}\text { Formal } \\
\text { employ- } \\
\text { ment }\end{array}$ & 1.0 & 1.0 & - & - \\
\hline $\begin{array}{l}\text { Informal } \\
\text { employ- } \\
\text { ment }\end{array}$ & 7.0 & 11.80 & $1.45-96.13$ & $0.02^{q}$ \\
\hline Not employed & 5.28 & 10.23 & $1.25-84.59$ & $0.03^{q}$ \\
\hline
\end{tabular}

" Significant at multivariate analysis

24]. It is possible that mothers in formal employment are very busy and would frequently forget to take the iron supplements. We found no association between age, parity, marital status and adherence.

\section{Study limitations}

This study used the visual analogue scale which allows patients to score their adherence in a range of 0-100 without being observed. This may have led to over estimation of adherence to iron supplements. This study assessed adherence for over 30 days yet in some cases the participants were received a supply of less than that in the hospital pharmacy. The patients are usually given a prescription by the attending clinician and asked to buy from private pharmacy when supply is inadequate. We feel this may not have had a very big impact since a month's supply of antenatal iron supplements cost less than a dollar which is usually affordable by most mothers.

Assessing adherence by measuring serum concentrations of radiologically labeled iron supplements would have been a more objective way of measuring adherence. However this is very costly and may not feasible in studies with large number of participants. 


\section{Conclusion}

The level of adherence to iron supplements among antenatal mothers in Mulago National Referral Hospital was low. The factors that were independently associated with adherence were: attendance of ANC four times or more, having more than 2 weeks supply of iron supplements, prior health education and informal education of the women. There's a need to ensure adequate drug supplies in health facilities and provision of adequate information about the supplements especially the benefits, side effects and how mothers can cope with these.

\section{Abbreviations}

ANC: antenatal clinic; Anti TB drugs: antituberculosis drugs; ARVs: antiretroviral drugs; VAS: visual analogue scale; WHO: World Health Organisation.

\section{Authors' contributions}

TSK was the principal investigator in this study. She made substantial contribution in conceiving and designing this study. TSK was involved in collection and interpretation of data and drafting the manuscript. SO was key in conceiving and designing this study. PK participated in interpretation of the data and revised the work for important intellectual content. NF made substantial contribution in designing this study, interpretation of the data, and revising the manuscript critically for important intellectual content. All authors read and approved the final manuscript.

\section{Acknowledgements}

We are grateful to all the mothers who agreed to participate in the study. We would like to acknowledge the generous intellectual contributions of Professor Florence Mirembe, Dr. Regina Nakiranda, Dr. Esau Wasswa and Dr. Mike Kagawa towards this study. We are grateful to the following midwives Sr. Jane Francis Nabbosa, Florence Namirembe, Getrude Lunkuse and Flavia Mirembe, who were wonderful research assistants and participated wholly in the process of data collection.

\section{Competing interests}

The authors declare that they have no competing interests.

\section{Availability of data and materials}

The data is available in the manuscript.

\section{Consent for publication}

All participants provided an informed written consent and no personal details or images were collected.

\section{Ethics approval and consent to participate}

The study was approved by Makerere University School of Medicine Research and Ethics Committee. All participants were recruited after an informed written consent.

\section{Funding}

The study was funded by the Belgium Technical Co-operation. NF was supported by Training Health Researchers into Vocational Excellence in East Africa (THRIVE), a Wellcome trust supported project.

\section{Publisher's Note}

Springer Nature remains neutral with regard to jurisdictional claims in published maps and institutional affiliations.

Received: 25 July 2016 Accepted: 19 October 2017

Published online: 25 October 2017
References

1. Abu-Ouf NM, Jan MM. The impact of maternal iron deficiency and iron deficiency anemia on child's health. Saudi Med J. 2015;36(2):146-9.

2. Ononge S, Campbell O, Mirembe F. Haemoglobin status and predictors of anaemia among pregnant women in Mpigi, Uganda. BMC Res Notes. 2014;7:712.

3. Ministry of Health, editor. National Anaemia Policy, health. Ministry of Health: Uganda; 2002. p. 8-13.

4. Hope CJ, Wu J, Tu W, Young J, Murray MD. Association of medication adherence, knowledge, and skills with emergency department visits by adults 50 years or older with congestive heart failure. Am J Health Syst Pharm. 2004;61(19):2043-9.

5. Oriji VK, Enyindah CE, Nyeche S. Factors determining compliance to routine iron supplementation in pregnancy at the University of Portharcout Teaching Hospital. Niger J Med. 2011;20(1):131-4.

6. Dairo MD, Lawoyin TO. Demographic factors determining compliance to iron supplementation in pregnancy in Oyo State, Nigeria. Niger J Med. 2006:15(3):241-4

7. Secka BC, Jacksona RT. Determinants of compliance with iron supplementation among pregnant women in Senegal. Public Health Nutr. 2008;11(06):596-605.

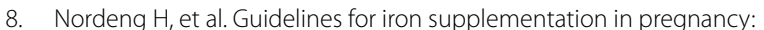
compliance among 431 parous Scandinavian women. Eur J Clin Pharmacol. 2003;59(2):163-8.

9. Martin LR, et al. The challenge of patient adherence. Ther Clin Risk Manag 2005:1(3):189.

10. Kalichman SC, et al. A simple single-item rating scale to measure medication adherence: further evidence for convergent validity. J Int Assoc Phys AIDS Care (JIAPAC). 2009:8(6):367-74.

11. Osterberg $L$, Blaschke T. Adherence to medication. N Engl J Med. 2005;353(5):487-97.

12. Bondarianzadeh $D$, et al. Low compliance with the iron supplementation program among pregnant women in the rural areas of Kerman District, IR Iran. Nutr Res. 1998;18(6):945-52.

13. Price DD, et al. The validation of visual analogue scales as ratio scale measures for chronic and experimental pain. Pain. 1983;17(1):45-56.

14. Galloway R, McGuire J. Determinants of compliance with iron supplementation: supplies, side effects, or psychology? Soc Sci Med. 1994;39(3):381-90.

15. Aikawa $R$, et al. Why do adult women in Vietnam take iron tablets? BMC Public Health. 2006;6(1):144

16. Klemm RD, et al. Are we making progress on reducing anaemia in women?. In: The USAID Micronutrient and Child Blindness Project: 1825 Connecticut Ave., NW Washington, DC 20009 USA. 2011. p. 1-45.

17. Mora JO. Iron supplementation: overcoming technical and practical barriers. J Nutr. 2002;132(4):853S-5S.

18. Yekta $Z$, et al. Predicting factors in iron supplement intake among pregnant women in urban care setting. J Res Health Sci. 2008;8(1):39-45.

19. Habib F, et al. Compliance to iron supplementation during pregnancy. J Obstet Gynaecol. 2009;29(6):487-92.

20. Cunningham FG, et al. William's Obstetrics. In: Cunningham FG, et al. editors. Mc Graw Hill; 2007.

21. Melamed N, et al. Iron supplementation in pregnancy-does the preparation matter? Arch Gynecol Obstet. 2007;276(6):601-4.

22. Mwadime RKN, et al. Overcoming barriers to effective anemia interventions during antenatal services in Uganda. Kampala: IPH Makerere; 2002. p. 11-38.

23. Ekström $\mathrm{E}$, et al. Adherence to iron supplementation during pregnancy in Tanzania: determinants and hematologic consequences. Am J Clin Nutr. 1996;64(3):368-74.

24. Muture BN, et al. Factors associated with default from treatment among tuberculosis patients in Nairobi province, Kenya: a case control study. BMC Public Health. 2011;11(1):696. 